Original Research Article

\title{
Drug utilization study in Cardiology outpatient department at a tertiary care hospital
}

\author{
Indu Slathia, Pradeep R. Jadhav*, Pooja Deb, Shashwat Verma
}

Department of Pharmacology, MGM Medical College and Hospital, Navi Mumbai, Maharashtra, India

Received: 11 July 2017 Accepted: 05 August 2017

*Correspondence to:

Dr. Pradeep R. Jadhav, Email: docpradeepj@gmail.com

Copyright: (C) the author(s), publisher and licensee Medip Academy. This is an openaccess article distributed under the terms of the Creative Commons Attribution NonCommercial License, which permits unrestricted noncommercial use, distribution, and reproduction in any medium, provided the original work is properly cited.

\begin{abstract}
Background: Cardiovascular diseases are the most frequent cause of morbidity and mortality throughout the world particularly in South Asian population. With advent of newer, highly efficacious heterogeneous drugs and changing treatment guidelines, there's a need to identify the cardiologist preference and prescribing patterns for rational utilization.

Methods: It was an open label, prospective, cross-sectional, descriptive type of study conducted in Cardiology Outpatients at a Tertiary care hospital, Navi Mumbai. The study included 100 patients suffering from cardiovascular diseases attending cardiology outpatient department from October 2016 to March 2017. Informed consent was obtained and the currently prescribed drug details were recorded from prescription. The data was analysed for WHO core prescribing indicators and different types of drugs prescribed.

Results: The average number of drug products prescribed was 3.4. Most commonly prescribed drugs were Antiplatelets (23\%) followed by Statins (19.71\%), $\beta$ blockers (16\%), Nitrates $(11.70 \%)$, Angiotensin converting enzyme inhibitors $(8.03 \%)$, Calcium channel blockers $(5.50 \%)$, Angiotensin receptor blockers (4.70\%), Diuretics (2.55\%), Anticoagulant (1.83\%), $\alpha+\beta$ blocker $(1.46 \%)$, Cardiac glycosides $((1.09 \%)$, Potassium sparing diuretic and central sympatholytics. Majority of drugs were prescribed as single drugs (79.88\%) while $20.11 \%$ as fixed dose combination (FDC). The combination of Telmisartan + Hydrochlorthiazide was the commonest prescribed FDC. Majority drugs were prescribed from NEDL 2015, but documented low generic prescribing.

Conclusions: Antiplatelet and Statins dominated the prescribing pattern with high prescribing trend from national essential drug list, but showed scope for improvement in encouraging the cardiologist to prescribe by generic name.
\end{abstract}

Keywords: Cardiology, Drug utilization, Prescribing pattern

\section{INTRODUCTION}

Drug utilization research was defined by the WHO in 1977 as "The marketing, distribution, prescription, and use of drugs in a society, with special emphasis on the resulting medical, social and economic consequences". 1 The therapeutic practice is expected to be primarily based on evidence provided by pre marketing clinical trials, but complementary data from post marketing period are needed to provide an adequate basis for improving drug therapy. ${ }^{1-5}$
The ultimate goal of drug utilization research must be to assess whether drug therapy is rational or not. Drug utilization study is important to realize that inappropriate use of drugs represent a potential hazard and an unnecessary expense to the patients. This necessitates a periodic review of pattern of drug utilization to ensure safe and effective treatment. ${ }^{1-5}$

Recent studies have shown that cardiovascular diseases are the most frequent cause of morbidity and mortality throughout the world. The risk of cardiovascular disease 
has increased in South Asians also. ${ }^{6}$ The drastic change in the lifestyle of the population during the $21^{\text {st }}$ century has had a great impact on health, especially cardiovascular diseases. ${ }^{7}$ Due to implementation of effective prevention and treatment strategies as well as life style modification the developed countries has decreased CVD burden. By contrast, CVD has increased in developing countries and also threatened by poor diet, sedentary life style and obesity, smoking, hypertension, high blood cholesterol and diabetes mellitus. ${ }^{8}$ So our country India is a fertile ground for CVD with major health care burden socially and economically. ${ }^{7}$ The common cardiovascular diseases include congestive heart failure, hypertension, cardiac arrhythmia, cerebrovascular accident, coronary artery disease, ischemic heart disease like angina pectoris and myocardial infarction, aneurysm, atherosclerosis and peripheral vascular diseases. ${ }^{9}$ The prevalence rate of risk factors for CVD has been rapidly rising within India. Premature mortality in terms of years of life lost because of CVD in India increased by $59 \%$, from 23.2 million to 37 million. ${ }^{10}$

Various heterogeneous classes of drugs are used in the treatment of cardiovascular diseases. With the advent of newer, highly efficacious and safer drugs, there's a need to identify cardiologist preference and prescribing behavior in cardiovascular conditions. Studies of drug utilization in cardiovascular department have shown varying pattern of drug utilization among different institutions. ${ }^{11,12}$ Therefore, this study was conducted to obtain data on current prescribing pattern and drug utilisation trend of cardiologist at a tertiary care hospital with ultimate goal to promote rational use of drugs among prescribers.

\section{METHODS}

This was an open label, prospective, cross sectional, descriptive study conducted at Department of Cardiology, tertiary care teaching hospital, Navi-Mumbai, Maharashtra, India. The study protocol was approved by Institutional Ethics Committee of MGM Medical college and hospital Navi -Mumbai, Maharashtra, India on $7^{\text {th }}$ October 2016.

The study duration was 6 months from October 2016 to March 2017. One hundred $(n=100)$ adult patients of either sex having cardiovascular disease with or without co morbidity attending Cardiology OPD were explained the purpose and procedure of the study. Those fulfilling inclusion and exclusion criteria were enrolled and written informed consent taken. Participant's prescription and demographic details were recorded on case record form (CRF).

\section{Inclusion criteria}

- Adult patient of either sex with cardiovascular disease with or without comorbidity.

- Patient willing to participate and give voluntary informed consent.

\section{Exclusion criteria}

- $\quad$ Age $<18$ years and $>65$ Years

- $\quad$ Patient not willing to participate and give informed consent.

- Patients with non-cardiovascular disease

- Patients with acute cardiovascular emergencies

- Patients admitted in intensive care unit/ In patient ward

- Patient with history of Psychiatry illness or on psychotropic medication

- $\quad$ Patient with repeat attendance.

\section{Data analysis}

WHO core prescribing indicators and additional parameters analysed:

- Average number of drugs prescribed per prescription

- Commonest type and class of drugs prescribed.

- Percentage of drugs prescribed as FDC's.

- $\quad$ Percentage of drugs prescribed by generic name vs brand name.

- Percentage of drugs prescribed from National Essential Drug List (NEDL-2015). ${ }^{13}$

- Percentage of encounters with an injection prescribed.

- $\quad$ Percentage of encounters with antibiotic prescribed.

\section{Statistical analysis}

Data was entered in MS-Excel 2007. Descriptive statistics was used to describe the data. Data was expressed in actual number, percentage and mean with standard deviation.

\section{RESULTS}

A total of 100 prescriptions were analysed and a total of 343 drug products were prescribed to the patients. Thus the average number of drug products prescribed in this study was 3.4 (Table 1).

\section{Table 1: Details of drug utilization} prescribing indices.

\begin{tabular}{|ll|}
\hline WHO prescribing indices & Value \\
\hline $\begin{array}{l}\text { Average number of drug products per } \\
\text { encounter }\end{array}$ & 3.4 \\
\hline $\begin{array}{l}\text { Percentage of drugs prescribed by generic } \\
\text { name }\end{array}$ & $6.20 \%$ \\
\hline $\begin{array}{l}\text { Percentage of encounters with an antibiotic } \\
\text { prescribed }\end{array}$ & $0.73 \%$ \\
\hline $\begin{array}{l}\text { Percentage of encounters with an injection } \\
\text { prescribed }\end{array}$ & $0.73 \%$ \\
\hline $\begin{array}{l}\text { Percentage of drugs prescribed from } \\
\text { National Essential Drug List (2015) }\end{array}$ & $82.80 \%$ \\
\hline
\end{tabular}

Patients were prescribed drugs from different classes of cardiovascular drugs like antiplatelet, antihypertensive 
drugs, anticoagulants, antianginal etc. In this study the most commonly prescribed drugs were Antiplatelet (23\%) followed by Statins (19.71\%), $\beta$ blockers (16\%), Nitrates $(11.70 \%)$, Angiotensin converting enzyme inhibitors $(8.03 \%)$, Calcium channel blockers $(5.50 \%)$, Angiotensin receptor blockers $(4.70 \%)$, Diuretics $(2.55 \%)$, Anticoagulant $(1.83 \%), \alpha+\beta$ blocker $(1.46 \%)$, Cardiac glycosides, Potassium sparing diuretic and central sympatholytics $(1.09 \%)$ as depicted in Figure 1. Amongst antiplatelet drugs, aspirin and clopidogrel were preferred and commonly prescribed whereas amongst statins, atorvastatin was preferred.

Majority of the drugs were prescribed as single drug products $(79.88 \%)$, however $20.12 \%$ were prescribed in the form of fixed dose combination (FDC). The combination of Telmisartan + Hydrochlorthiazide was the commonest prescribed FDC (23.19\%) followed by aspirin + atorvastatin $(20.29 \%)$ and furesmide + spironolactone (17.39\%) as shown in Figure 2.

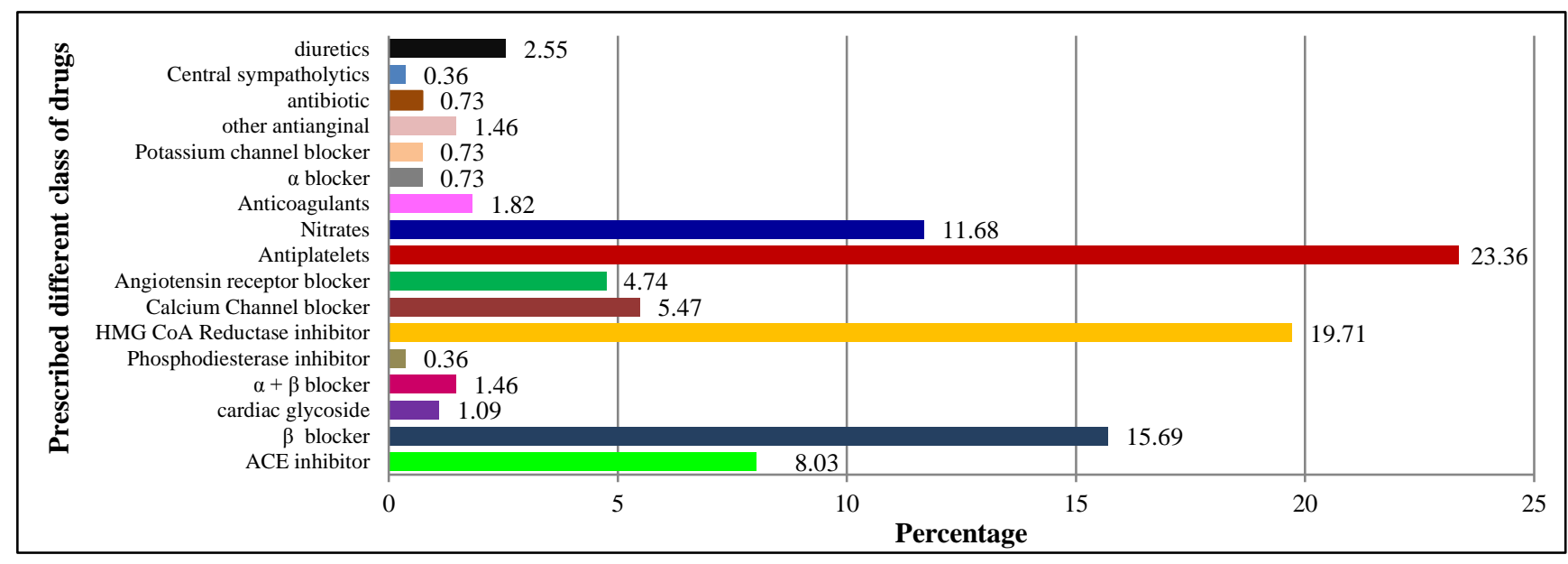

Figure 1: Different classes of prescribed drugs in cardiology outpatient department.

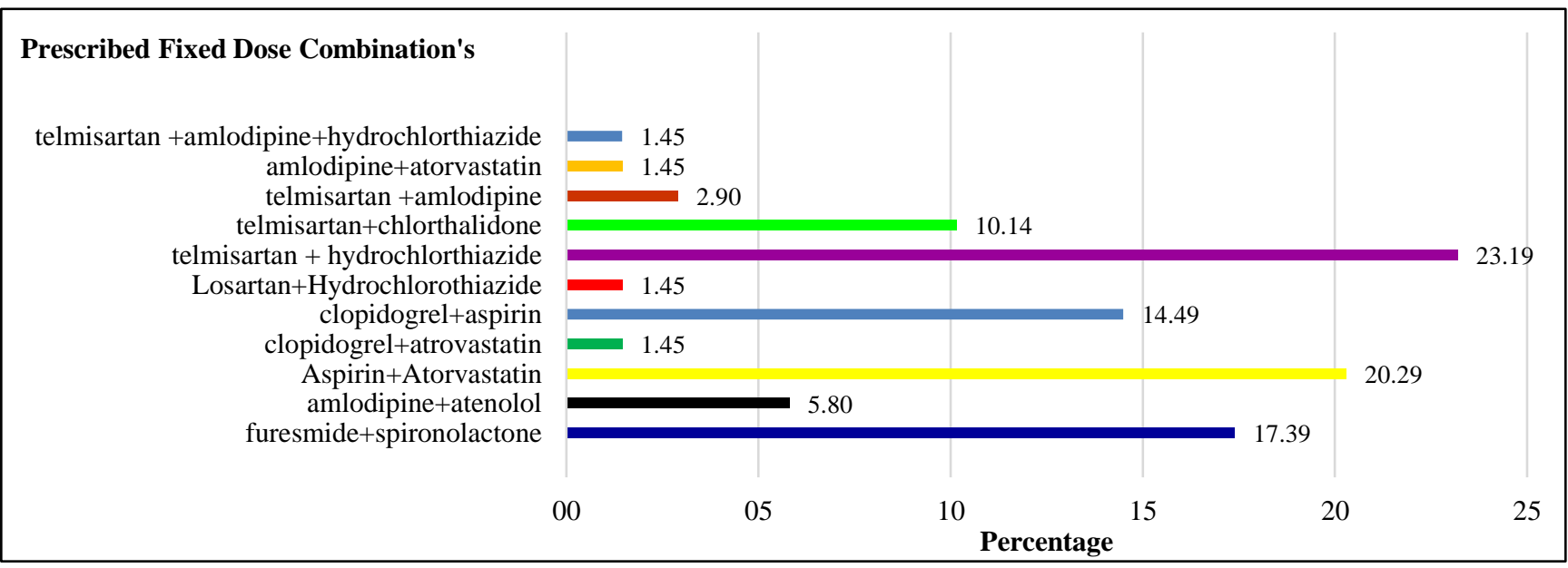

Figure 2: Different prescribed fixed dose combinations.

Other FDC's included aspirin + clopidogrel (14.4\%), telmisartan + chlorthalidone $(10.4 \%)$ amlodipine + atenolol $(5.80 \%)$, telmisartan + amlodipine $(2.90 \%)$, amlodipine + atorvastatin $(1.45 \%)$, losartan + hydrochlorothiazide $(1.45 \%)$, telmisartan + amlodipine + hydrochlorothiazide $(1.45 \%)$ and clopidogrel + atorvastatin $(1.45 \%)$.
In this study, majority of the drugs were prescribed by brand/ trade name $(93.80 \%)$ while only $6.2 \%$ were prescribed by generic name (Figure 3). Thus, the study documents preference for branded drugs /trade names instead of generic prescribing. In this study, $82.8 \%$ drugs were prescribed from National Essential Drug list (NEDL 2015) whereas only $17.2 \%$ accounted for non-essential drugs as shown in Figure 4. 


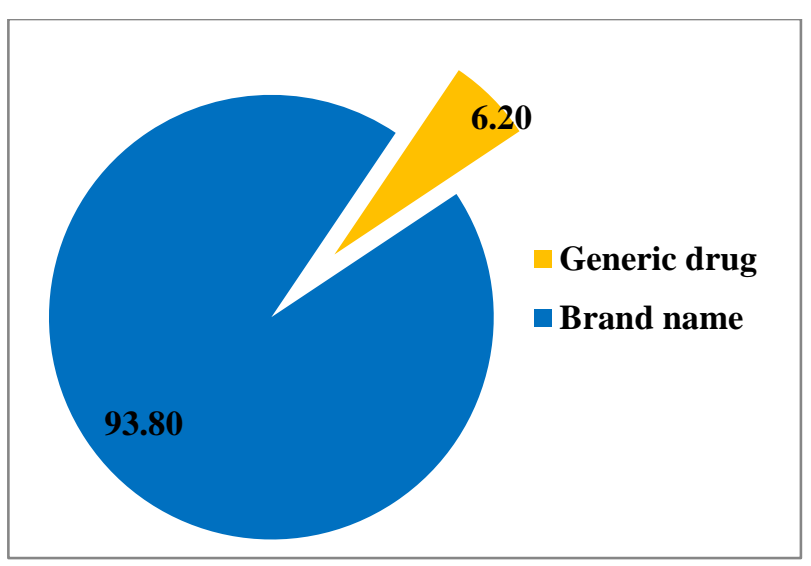

Figure 3: Percentage of drug prescribed by generic versus brand name.

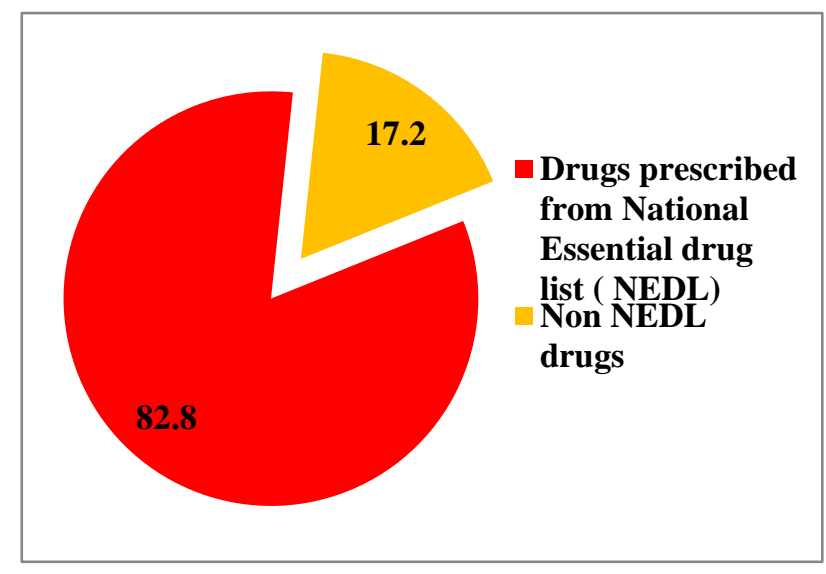

Figure 4: Percentage of drugs prescribed from NEDL.

Out of single drugs prescribed only $0.73 \%$ were antibiotics given in injectable form. These injectable antibiotics were prescribed to patients with rheumatic heart disease.

\section{DISCUSSION}

Cardiovascular diseases are the leading cause of morbidity and mortality throughout the world, with increasing incidences in South Asian countries including India. ${ }^{6}$ Recently, there has been a rigorous effort to ensure rational use of drugs for which WHO has identified specific drug use indicators, adoption of generic drugs and adherence to Essential drug list (EDL). ${ }^{1-3}$ The present study was undertaken to obtain data on current prescribing pattern and drug utilization trend of cardiologist at a tertiary care hospital with ultimate goal to promote rational use of drugs among prescribers.

In this study, we found that the average number of drug products prescribed by cardiologist were 3.4. Previous studies have documented that the average number of drugs prescribed in cardiology outpatient department ranges from 7 to $8 .^{14,15}$ Our study documented lower average number of drugs per prescription in comparison to previous studies. Thus, we found there was restrain on polypharmacy (more than 3 drugs). Ideally it is preferred to keep average number of drugs lower as polypharmacy leads to increased risk of drug to drug interactions, prescribing errors and also increases the cost of therapy.

In our study, majority (82.8\%) of drugs were prescribed from National Essential Drug list, this was comparable with study conducted in Farahana et al, in Bangladesh where drug prescribed from essential drug list was $70 \% .^{14}$ Our study documented higher preference and selection of Essential drugs. The possible reason for this higher value could be the prescriber's knowledge, understanding and importance of essential drug concept. The proper selection of essential drug useful for dealing with the majority of health problem cuts down the number of unnecessary product to be manufactured promoted and marketed. Thus selection of essential drugs promotes rational use of drugs and is recommended by National and International guidelines. ${ }^{1-3,13}$

In our study, most of the drugs prescribed by cardiologists were by brand/ trade names $(93.8 \%)$ rather than generic, which constituted only $6.2 \%$. The low selection of generic drugs were similar to study conducted by Sandoz et al, in which it was $6 \% .{ }^{16}$ However studies conducted by Junid et al, in Malaysia (45.2\%) and Nwidu et al, in Nigeria (37.4\%) have documented higher prescribing of drugs by generic name. ${ }^{17,18}$ It is preferable to prescribe drugs by generic name as it avoids duplication of drug products and provides low cost which can translate into cost effective drug therapy. However, the issues of substandard manufacturing of generic drugs needs to be accounted for, which generally lowers the therapeutic efficacy of drugs.

In our study, we found that the most commonly prescribed drugs were Antiplatelet drugs (23\%) followed by Statins (19.71\%), $\beta$ blockers (16\%), Nitrates (11.70\%), Angiotensin converting enzyme inhibitors (8.03\%) and Calcium channel blockers. Amongst antiplatelet drugs aspirin and clopidogrel were the most commonly prescribed whereas amongst statins, atorvastatin was commonly prescribed drug. A study conducted by Afroj et al, in Bangladesh, documented that the most commonly prescribed cardiovascular drug in cardiology department were aspirin and clopidogrel 278 (93\%) followed by tab atorvastatin, ramipril and amlodipine. ${ }^{14}$ Our study showed similar trend of commonly prescribed drugs which were Antiplatelets followed by statins but documented higher prescribing trend of beta blockers instead of ACE Inhibitors and Calcium channel blockers. Studies conducted by Zafar et al, and Divya et al, in hypertensive patients have documented the preference for Beta-blockers and they were the commonly prescribed drugs. ${ }^{19,20}$

It was observed in the present study that $20.11 \%$ were prescribed as fixed dose combinations. The combination of Telmisartan + Hydrochlorthiazide was the commonest prescribed FDC (23.19\%) followed by aspirin + atorvastatin $(20.29 \%)$ and furosemide + spironolactone (17.39\%). These combinations reflect the high prevalence 
of ischemic heart disease and hypertension burden among study population.

The telmisartan/hydrochlorothiazide is an effective, welltolerated antihypertensive combination which shows improved drug adherence because telmisartan has long half-life and offers the advantage of one-pill-a-day regimen. The combination of telmisartan with hydrochlorothiazide is a logical step because numerous previous studies have demonstrated that sodium depletion enhances the antihypertensive efficacy of drugs interfering with the activity of the renin-angiotensin system (RAS). In accordance with past experience using similar compounds blocking the RAS, several controlled studies have now demonstrated that the fixed-dose combination of telmisartan / hydrochlorothiazide is superior in lowering blood pressure than either telmisartan or hydrochlorothiazide alone. ${ }^{21}$ Previous study conducted by Manjhi et al, to analysing the prescription pattern of fixed dose drug combination in cardiology department in a tertiary care hospital documented that, aspirin+ atorvastatin (16.92\%) followed by telmisartan + hydrochlorthiazide $(11.53 \%)$ and furosemide + spironolactone $(10.76 \%)$ were commonly prescribed cardiovascular FDCs. ${ }^{7}$ These findings are similar to the FDC's prescribed in our study. Whereas, study conducted by Vijayakumar et al, on FDC has documented amlodipine + atenolol to be commonly prescribed FDC combination $(12.8 \%)$, followed by aspirin + clopidogrel $(11.1 \%)$, and telmisartan + hydrochlorothiazide $(9.8 \%) .^{22}$

Thus, the prescribing pattern and trend of cardiologist in our study was knowledge based and in accordance with the current treatment guidelines for cardiovascular diseases. Antiplatelet drugs and Statins dominated the prescribing pattern with high prescribing trend from National essential drug list. However, there is a need to sensitize the cardiologist and make them aware to adopt generic drugs, so as to ensure cost effective and rational utilization of drugs.

The present study had certain limitations. It was a crosssectional, quantitative type of drug utilization study conducted in a single hospital setup with minimum sample size as per the WHO guidelines. The qualitative assessment of individual prescription was not carried out. The study duration was for 6 months and hence was not able to capture the seasonal variations in prescribing trend.

\section{CONCLUSION}

Antiplatelet drugs and Statins dominated the prescribing pattern with high prescribing trend from national essential drug list, but showed scope for improvement in encouraging the cardiologist to prescribe drugs by generic name.

Funding: No funding sources Conflict of interest: None declared
Ethical approval: The study was approved by the Institutional Ethics Committee

\section{REFERENCES}

1. World Health Organization (WHO) and International Network for Rational Use of Drugs. How to Investigate Drug Use in Health Facilities: Selected Drug Use indicators. Geneva, Switzerland: WHO; 1993.

2. Dukes MNG. Drug utilization studies: methods and uses. World Health Organization Regional Publications. European series; 45. Copenhagen, Denmark. Available at: http://apps.who.int/medicinedocs/documents/s21868e n/s21868en.pdf.

3. World Health Organization. Introduction to Drug Utilization Research. Oslo, Norway: WHO; 2003. Available http://apps.who.int/medicinedocs/en/d/Js4876e/

4. Lee D, Bergman U. Studies of drug utilization. In: Storm LB, editor. Pharmacoepidemiology. Chichester, UK: John Wiley and Sons; 2005:401-417.

5. Rubin RJ, Altman WM, Mendelson DN. Health care expenditures for people with diabetes mellitus, 1992. J Clin Endocrinol Metab. 1994 Apr;78(4):809A-809F.

6. Anand SS, Yusuf S, Vuksan V, Devanesen S, Teo KK, Montague PA, et al. Differences in risk factors, atherosclerosis, and cardiovascular disease between ethnic groups in Canada: The Study of Health Assessment and Risk in Ethnic groups (SHARE). Lancet. 2000 Jul 22;356(9226):279-84.

7. Manjhi PK, Mohan L, Kumar M, Dikshit H, Singh B, Pathak A, et al. Prescription pattern of fixed dose drug combination in cardiology department in a tertiary care hospital. International Journal of Basic \& Clinical Pharmacology. 2016;5(3):951-55.

8. Ara S. A literature review of cardiovascular disease management programs in managed care populations. $\mathrm{J}$ Manag Care Pharm. 2004 Jul-Aug;10(4):326-44.

9. World Health Statistics. Cause-specific mortality and morbidity. Available at: http://www.who.int/whosis/whostat/EN_WHS09_Ta ble2.pdf

10. Prabhakaran D, Jeemon P, Roy A. Cardiovascular Diseases in India: Current Epidemiology and Future Directions. Circulation. 2016 Apr 19;133(16):160520.

11. Jankovió SM, Dejanovió SMD. Drug utilization trends in clinical hospital center Kragujevac from 1997 to 1999. Indian J Pharmacol. 2001;33:29-36.

12. Sutharson L, Hariharan RS, Vamsadhara C. Drug utilisation study in diabetology outpatient setting of a tertiary hospital. Indian J Pharmacol. 2003;35:237-40.

13. National List of Essential Medicines of India 2015. Ministry of Health and Family Welfare, Government of India. Available at: http://www.pharmaceuticals.gov.in/NLEM.pdf.

14. Afroj F, Parveen F, Ara F, Iqbal M, Saha R, Rozario R. Patterns of Drug Utilization in Cardiology 
Department of a Tertiary Level Hospital in Bangladesh. Bangladesh Journal of Physiology and Pharmacology. 2014;28(1-2):1-4.

15. Rajanandh MG, Ramasamy C, Khan I. Pattern of cardiovascular drugs use in outpatients in a tertiary care hospital. Asian Journal of Pharmaceutical and Clinical Research. 2012;5(1):109-112.

16. Sandozi T, Naushe F. Drug utilization study in ischemic heart diseases associated with diabetes and hypertension. International Journal of Pharma and Bio Sciences. 2010;1(3):1-4.

17. Al-Junid SM, Ezat WP, Surianti S. Prescribing patterns and drug cost among cardiovascular patients in Hospital Universiti Kebangsaan Malaysia. Med J Malaysia. 2007 Mar;62(1):59-65.

18. Nwidu LL, Essien GE, N-Chris EE. Pattern of prescription in cardiovascular diseases management in Port Harcourt city, Nigeria. Journal of Pharmacy Research. 2009;2(10):1653-58.

19. Zafar F, Ali H, Naveed S, Korai OU, Rizvi M, Naqvi GR, et al. Drug Utilization Pattern in Cardiovascular Diseases: A Descriptive Study in Tertiary Care
Settings in Pakistan. $\mathbf{J}$ Bioequiv Availab. 2015;7(1):59-62.

20. Divya G, Devi AR, Lakshmi P. Prescribing Patterns of Antihypertensive Drugs in Cardiology Department. Inventi Rapid: Pharmacy Practice. 2014; 2014(3):1-6.

21. Maillard MP, Burnier M. Is the fixed-dose combination of telmisartan and hydrochlorothiazide a good approach to treat hypertension? Vascular Health and Risk Management. 2007;3(3):265-278.

22. Vijayakumar TM, Poovi G, Swaroop TVSS, Thirumurugan G, Dhanaraju MD. Prescribing pattern of fixed dose combinations: focus on cardiovascular drugs in outpatient department of private hospitals. Journal of pharmacology and toxicology. 2010;5(5):215-21.

Cite this article as: Slathia I, Jadhav PR, Deb P, Verma S. Drug utilization study in Cardiology outpatient department at a tertiary care hospital. Int J Basic Clin Pharmacol 2017;6:2276-81. 